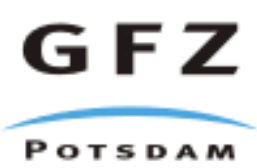

Originally published as:

Haberland, C., Rietbrock, A., Schurr, B., Brasse, H. (2003): Coincident anomalies of seismic attenuation and electrical resistivity beneath the southern Bolivian Altiplano plateau. -

Geophysical Research Letters, 30, 18, 1923

DOI: 10.1029/2003GL017492 


\section{Coincident anomalies of seismic attenuation and electrical resistivity beneath the southern Bolivian Altiplano plateau}

Christian Haberland ${ }^{1}$, Andreas Rietbrock ${ }^{2,5}$, Bernd Schurr ${ }^{1,3}$, and Heinrich Brasse $^{4}$

Christian Haberland, GeoForschungsZentrum Potsdam, Telegrafenberg, 14473 Potsdam, Germany, haber@gfz-potsdam.de

Andreas Rietbrock, Institute of Geosciences, University Potsdam, PO 601553, 14415 Potsdam, Germany, andreas@geo.uni-potsdam.de

Bernd Schurr, CTBTO, IDC/Scientific Methods, Wagramerstr. 5, A-1400 Vienna, Austria, bernd.schurr@ctbto.org

Heinrich Brasse, FU Berlin, Malteserstr. 74-100, 12249 Berlin, Germany, h.brasse@geophysik.fu-berlin.de

${ }^{1}$ GeoForschungsZentrum Potsdam

${ }^{2}$ University of Potsdam

${ }^{3}$ CTBTO Wien

${ }^{4} \mathrm{FU}$ Berlin

${ }^{5}$ now at University of Liverpool 


\section{Abstract.}

Reassessment of local earthquake data from the ANCORP seismological network allowed the calculation of 3D attenuation $\left(Q_{p}\right)$ tomographic images of crust and upper mantle beneath the southern Bolivian Altiplano around $21^{\circ} \mathrm{S}$. The images reveal a low- $Q_{p}$ middle and lower crust and a moderate$Q_{p}$ upper mantle beneath the southern Altiplano. Beneath the recent magmatic arc, $Q_{p}$ is not significantly decreased at this latitude. The distribution of crustal $Q_{p}$ coincides with the variation of electrical resistivity, thus limiting the possible mechanisms causing the anomalies. Our findings support the hypothesis that partial melts in middle and lower crust beneath the Altiplano are present on a large scale. We see no evidence for a shallow asthenosphere beneath the southern Altiplano. 


\section{Introduction}

The tectonic situation at the western South American continental margin is dominated by two interdependent processes: the subduction of the oceanic Nazca plate and the formation of the world's second largest mountain plateau, the Altiplano-Puna high plateau (Fig. 1). The plateau is considered to be mainly a result of crustal thickening $(>70 \mathrm{~km}$, [Zandt et al., 1994]) due to tectonic shortening, however, in absence of a continental collision [Isacks, 1988; Allmendinger and Gubbels, 1996; Whitman et al., 1992]. Volcanism has ocurred throughout the plateau during its formation, but most of the recent subduction related andesitic magmatism is concentrated at the western plateau border, where it forms the magmatic arc in the Western Cordillera [Allmendinger et al., 1997]. Widespread silicic magmatism (e.g., ignimbrites) indicates episodic large scale crustal melting [de Silva, 1989], and it has been suggested that thermal weakening of the crust has played an important role in the formation of the plateau [e.g., Isacks, 1988].

In this paper we use the attenuation of seismic $\mathrm{P}$ waves of local earthquakes to study the structure and state of crust and upper mantle of the southern Bolivian Altiplano (between $20.5^{\circ}$ and $22.0^{\circ} \mathrm{S}$ ). Seismic signals are subject to attenuation due to different mechanisms such as scattering, geometrical spreading, and inelastic dissipation (e.g., high temperatures, presence of fluids or partial melts [Johnston et al., 1979; Mavko, 1980]). In previous studies the distribution of the attenuation yielded insight into processes of magma generation and pathways beneath the Chilean forearc and arc [Haberland and Rietbrock, 2001] and the Argentine Puna [Schurr et al., 2002]. 
We compare the attenuation images with the spatial distribution of the electrical resistivity $(\rho)$ from magnetotelluric (MT) measurements. This parameter is sensitive to the occurrence of electronic conductors (e.g., graphite) and the presence of interconnected fluids (brines) and melts. The combination of both independent methods limits the number of possible mechanisms causing these anomalies and helps to reveal the structure and state of the plateau.

\section{Attenuation tomography, Data and Resolution}

We used methods in detail described in Haberland and Rietbrock [2001], thus only a rough outline is presented here. The attenuation of a seismic phase $\left(t_{i j}^{*}\right)$ can be attributed to the subsurface structure in a cumulative way along the corresponding ray path $r$ between earthquake $i$ and station $j\left(Q^{-1}(x, y, z)\right.$ is specific attenuation; $v(x, y, z)$ is velocity field) by $t_{i j}^{*}=\int_{p a t h_{i j}} Q^{-1}(r) v^{-1}(r) d r$. The $t_{i j}^{*}$ are deduced from the spectral falloff of the P phases [Rietbrock, 2001]. The damped least squares tomographic solution [Eberhart-Phillips, 1993; Thurber, 1983; Rietbrock, 1996] then reconstructs the distribution of intrinsic attenuation $Q^{-1}(x, y, z)$ from the $t_{i j}^{*}$. The model is defined by a regular grid. Because of predominantly sub-vertical ray-paths we expect vertical smearing in the easternmost parts of the model. Accordingly, east of $68^{\circ} \mathrm{S}$ we linked each two vertically adjacent nodes together [Thurber and Eberhart-Phillips, 1999]. With this procedure we intend to resolve larger structural units (e.g., lower crust or upper mantle) and to achieve a better vertical resolution. We set the inversion damping such that a balanced ratio between data variance and model variance was achieved. 
We used a total of $14.481 \mathrm{t}^{*}$ values of 1.195 carefully selected local earthquakes recorded by the PISCO and ANCORP temporary seismological networks [Graeber and Asch, 1999; Rietbrock et al., 1997; ANCORP Working Group, 1999]. These networks consisted of 24 and 32, respectively, continuously recording digital stations (sampling frequency $100 \mathrm{~Hz}$ ) with three component $1 \mathrm{~Hz}$ seismometers (Fig. 1). Compared to our previous study [Haberland and Rietbrock, 2001] we added about 100 well constrained events north of $22^{\circ} \mathrm{S}$ improving the resolution of the target volume. We resort to travel time picks and hypocenter locations from Graeber and Asch [1999] and Rietbrock et al. [1997]. The 3D inversion reduces the data variance by $86 \%$ to $0.0003367 s^{2}$.

In synthetic recovery tests we explored the restoring power of the tomographic inversion. In particular, we tested if attenuation restricted to crust or mantle beneath the plateau can be separated (Fig. 2). Along $21^{\circ} \mathrm{S}$ the synthetic structures are reproduced satisfactory as far east as $67^{\circ} \mathrm{W}$. Particularly, the crustal anomaly is well reproduced in shape and extent. The absolute values of the anomalies are slightly underestimated and the structures are broadened. Nevertheless, the successful reconstruction of the synthetic models suggests that we can distinguish between predominant crustal or upper mantle attenuation.

\section{Magnetotellurics}

In the MT experiment a total of 38 locations were occupied along a traverse around $21^{\circ} \mathrm{S}$ with a station spacing of $\sim 10 \mathrm{~km}$ by long-period magnetotelluric instruments (Fig. 1), covering a period range from $10 \mathrm{~s}$ to $3 \mathrm{~h}$. A 2-D resistivity model was derived by Brasse et al. [2002] employing the Gauß-Newton version of an inversion code developed by Rodi and Mackie [2001]. Details concerning processing, dimensionality, and strike 
analysis are described in Brasse et al. [2002] and Lezaeta [2001]. With the exception of some stations in the forearc and the eastern Altiplano, most data can be interpreted as two-dimensional. A careful examination of model space, including a sensitivity analysis concerning key model features (as resistivity values and spatial extent of the anomalies) was carried out by Schwalenberg et al. [2002]. Additionally, inter-station magnetic transfer functions were analyzed by Soyer and Brasse [2001], yielding basically similar models of resistivity distribution.

\section{Anomalies in Altiplano crust and upper mantle}

Fig. 3 shows the tomographic $Q_{p}$ reconstruction along $21^{\circ} \mathrm{S}$. The middle and lower crust beneath the Altiplano around $21^{\circ} \mathrm{S}$ is characterized by elevated attenuation. Over large volumes $Q_{p}$ values as low as 100 are recognized $\left(Q_{p}^{-1}=0.01\right)$. Although less well resolved, this anomaly diminishes to the north. Because of the lack of crustal events in the eastern part of the model, the uppermost model layers are not well resolved, resulting in a coupling between very shallow structure and station $t^{*}$ corrections $\left(\tau_{i}^{*}\right)$ in that region. We chose the $\tau_{i}^{*}$ damping such that no large anomalies directly related to the stationnearest structure occur in the shallow parts of the model. However, resulting large $\tau_{i}^{*}$ 's at the eastern stations (yellow and red squares in Fig. 3) indicate that low $Q_{p}$ values might also reach to upper crustal levels. The forearc and descending Nazca plate are characterized by low attenuation $\left(500 \leq Q_{p} \leq \infty\right)$. At $21^{\circ} \mathrm{S}$, crust and mantle beneath the recent magmatic arc show no significantly reduced $Q_{p}$ values in contrast to further south [Haberland and Rietbrock, 2001; Schurr et al., 2002]. However, it seems that the low- $Q_{p}$-anomaly is somehow connected with the crustal $Q_{p}$ anomaly beneath the region 
of widespread Neogene silicic magmatism further to the south (Altiplano Puna Volcanic Zone, APVC, Fig. 1). The mantle beneath the Altiplano shows only moderate attenuation which is in accordance with earlier attenuation studies [Whitman et al., 1992; Myers et al., 1998].

The MT data reveal generally high resistivities in the forearc and arc regions of the Andean crust along $21^{\circ} \mathrm{S}$ (Fig. $4 \mathrm{~A}$ ) . In contrast, a very good conductor appears at long periods below almost the entire (southern) Altiplano. Apparent resistivity curves keep falling even at longest periods and, correspondingly, phases stay above $45^{\circ}$. Similar to the $Q_{p}$ image, no low resistivity zone was found beneath the recent magmatic arc.

\section{Discussion}

As shown in Fig. 4 we see a strong coincidence in the distribution of $\rho$ and of $Q_{p}$ in the crust at $21^{\circ} \mathrm{S}$. Fig. $4 \mathrm{~B}$, in which $\rho$ and $Q_{p}$ values of all 5 by $5 \mathrm{~km}$ bins of the section are cross-plotted, demonstrates the coupled behaviour of the two parameters, suggesting that a common mechanism affects both parameters. The spatial remapping (Fig. $4 \mathrm{C}$ ) of the values, after they have been assigned according to a rough classification into high and low $\rho$ and $Q_{p}$, respectively, reveals large crustal domains with characteristic physical properties. The Q classification was set according to global models [Montagner and Kennett, 1996; Dziewonski and Anderson, 1981] in a way that average lithospheric values are distinguished from anomalous values or values representative for asthenosphere (threshold- $Q_{p}=250$ ). A $\rho$ threshold of $10 \Omega m$ was chosen to delineate good conductors. Slight variations of these values do not change the overall picture. 
The forearc and arc exhibit values representative for a cold crust (high $\rho$ and high $Q_{p}$, blue in Fig. $4 \mathrm{C}$ ). The strong anomalies beneath the Altiplano (red color in Fig. $4 \mathrm{C}$ ), which also correlate with regions of reduced seismic velocities [Yuan et al., 2000], are most probably caused by partial melts since they would enhance the attenuation [Mavko, 1980] and - if melts are interconnected - significantly reduce resistivity [Partzsch et al., 2000]. High temperatures alone would lower $Q_{p}$ but not $\rho$ sufficiently, and on the other hand, (solid) electrical conductors (e.g., graphite, another mechanism under discussion) would reduce $\rho$, but $Q_{p}$ should not be affected. Regions of dark blue color (in Fig. 4 C) could be related to more isolated fluids or melt pockets.

Widespread partial melting in the Altiplano crust has been previously proposed [Schmitz et al., 1996; Yuan et al., 2000; Brasse et al., 2002; Schilling and Partzsch, 2001; Schurr, 2001; Babeyko et al., 2002]. A thin $(\sim 1 \mathrm{~km})$ layer with very low velocity, situated at a depth of $\sim 20 \mathrm{~km}$ under the APVC region was interpreted as a magma body [Chmielowski et al., 1999; Beck and Zandt, 2002]. We suggest that the large scale low- $Q_{p} /$ low- $\rho$-anomaly revealed by this study also reflects this voluminous region of partial melt in the middle and lower crust. Our findings imply that the middle and lower crust beneath the southern Altiplano plateau (at present) has low rigidity and deforms in a ductile mode. This supports the concept of Isacks [1988] that crustal thickening was in part accomplished by diffuse shortening in a weak and ductile lower crust.

We deduce only moderate $Q_{p}$ values $\left(300 \leq Q_{p} \leq 500\right)$ beneath $50 \mathrm{~km}$ depth, which indicates the presence of lithospheric mantle beneath the southern Altiplano. For the asthenosphere we would expect much smaller values [e.g., Montagner and Kennett, 1996]. 
We associate this finding with the underthrusted Brazilian lithosphere [Whitman et al., 1992; Allmendinger and Gubbels, 1996] or newly formed lithosphere, and see no evidence for mantle delamination beneath this section of the plateau as proposed for the Puna further south [Schurr et al., 2002; Kay et al., 1994] or for the transition toward the Eastern Cordillera to the N-E [Beck and Zandt, 2002]. It has been suggested that thermal weakening of the lower crust has mainly been accomplished by increased mantle heat-flow during an episode with a thinned lithosphere [Isacks, 1988; Babeyko et al., 2002]. There is probably no need that this mechanisms has to persist until recently to allow for partial melt and related anomalies in the lower crust to date.

\section{Acknowledgments.}

The seismological components of the ANCORP and PISCO projects were financed by the Deutsche Forschungsgemeinschaft (DFG, SFB 267), the GeoForschungsZentrum Potsdam (GFZ) and the Free University of Berlin (FUB). FUB and GIPP (GFZ) provided instruments. Thanks to G. Asch, G. Chong, D. Comte, P. Lezaeta, P. Giese, V. Rath, R. Rößling, K. Schwalenberg, W. Soyer, P. Wigger, and H. Wilke for their efforts in the projects. We are indebted to B. Trumbull for helpful comments on the manuscript, to S. Sobolev for stimulating discussion, and to C. Braitenberg and an anonymous reviewer for constructive comments. All figures were made using GMT [Wessel and Smith, 1998].

\section{References}

Allmendinger, R., and T. Gubbels, Pure and simple shear plateau uplift, Altiplano-Puna, Argentina and Bolivia, Tectonophysics, 259, 1-13, 1996. 
Allmendinger, R., T. E. Jordan, S. M. Kay, and B. L. Isacks, The evolution of the Altiplano-Puna plateau of the central Andes, Annu. Rev. Earth Planet. Sci., 25, 139$174,1997$.

ANCORP Working Group, Seismic reflection image revealing offset of Andean subductionzone earthquake locations into oceanic mantle, Nature, 397, 341-344, 1999.

Babeyko, A., S. Sobolev, R. Trumbull, O. Oncken, and L. Lavier, Numerical models of crustal scale convection and partial melting beneath the Altiplano-Puna plateau, Earth Planet. Sci. Lett., 199, 373-388, 2002.

Beck, S. L., and G. Zandt, The nature of orogenic crust in the central Andes, J. Geophys. Res., 107, doi:10.1029/2000JB000,124, 2002.

Brasse, H., P. Lezaeta, V. Rath, K. Schwalenberg, W. Soyer, and V. Haak, The Bolivian Altiplano conductivity anomaly, J. Geophys. Res., 107, doi: 10.1029/2001JB000,391, 2002.

Chmielowski, J., G. Zandt, and C. Haberland, The central Andean Altiplano-Puna magma body, Geophys. Res. Lett., 26, 783-786, 1999.

de Silva, S., Altiplano-Puna Volcanic Complex of the central Andes, Geology, 17, 11021106, 1989.

Dziewonski, A. M., and D. L. Anderson, Preliminary reference Earth model, Phys. Earth Planet. Inter., 25, 297-356, 1981.

Eberhart-Phillips, D., Local earthquake tomography: Earthquake source regions, in Seismic Tomography: Theory and Practice, edited by H. Iyer and K. Hirahara, pp. 613-643, Chapman and Hall, New York, 1993. 
HABERLAND ET AL:: ATTENUATION AND RESISTIVITY BENEATH ALTIPLANO $\quad \mathrm{X}-11$

Graeber, F., and G. Asch, Three-dimensional models of $P$ wave velocity and $P$-to $S$ velocity ratio in the southern central Andes by simultaneous inversion of local earthquake data, J. Geophys. Res., 104, 20,237-20,256, 1999.

Haberland, C., and A. Rietbrock, Attenuation tomography in the western central Andes: A detailed insight into the structure of a magmatic arc, J. Geophys. Res., 106, 11,15111,167, 2001.

Isacks, B., Uplift of the central Andean plateau and bending of the Bolivian orocline, J. Geophys. Res., 93, 3.211-3.231, 1988.

Johnston, D., M. Toksös, and A. Timor, Attenuation of seismic waves in dry and saturated rocks, II, Mechanisms, Geophysics, 44, 691-711, 1979.

Kay, S. M., B. Coira, and J. Viramonte, Young mafic back arc volcanic rocks as indicators of continental lithospheric delamination beneath the Argentine Puna plateau, central Andes, J. Geophys. Res., 99, 24,323-24,339, 1994.

Lezaeta, P., Distortion analysis and 3-D modelling of magnetotelluric data in the southern central Andes, Ph.D. thesis, Freie Universität Berlin, 2001.

Mavko, G. M., Velocity and attenuation in partially molten rocks, J. Geophys. Res., 85, 5173-5189, 1980.

Montagner, J., and B. Kennett, How to reconcile body-wave and normal-mode reference earth models?, Geophys. J. Int., 125, 229-248, 1996.

Myers, S. C., S. Beck, G. Zandt, and T. Wallace, Lithospheric-scale structure across the Bolivian Andes from tomographic images of velocity and attenuation for $P$ and $S$ waves, J. Geophys. Res., 103, 21,233-21,252, 1998. 


\section{X - 12 HABERLAND ET AL.: ATTENUATION AND RESISTIVITY BENEATH ALTIPLANO}

Partzsch, G., F. Schilling, and J. Arndt, The influence of partial melting on the electrical behavior of crustal rocks: Laboratory examinations, model calculations and geological interpretations, Tectonophysics, 317, 189-203, 2000.

Rietbrock, A., Entwicklung eines Programmsystems zur konsistenten Auswertung grosser seismologischer Datensätze mit Anwendung auf die Untersuchung der Absorptionsstruktur der Loma-Prieta-Region, Kalifornien, Ph.D. thesis, Ludwig-MaximiliansUniversität, Munich, Germany, 1996.

Rietbrock, A., $P$ wave attenuation structure in the fault area of the 1995 Kobe earthquake, J. Geophys. Res., 106, 4141-4154, 2001.

Rietbrock, A., C. Haberland, G. Asch, G. Chong, and P. Giese, ANCORP'96 - Seismicity along the ANCORP traverse in northern Chile, Eos Trans. AGU, 78(46), Fall Meet. Suppl., F716, 1997.

Rodi, W., and R. L. Mackie, Nonlinear conjugate gradients algorithm for 2-D magnetotelluric inversions, Geophysics, 66, 174-187, 2001.

Schilling, F., and G. Partzsch, Quantifying partial melt fraction in the crust beneath the Central Andes and the Tibetan Plateau, Phys. Chem. Earth (A), 26, 239-246, 2001.

Schmitz, M., W.-D. Heinsohn, and F. R. Schilling, Seismic, gravity and petrological evidence for partial melt beneath the thickened central Andean crust (21-23 S), Tectonophysics, 270, 313-326, 1996.

Schurr, B., Seismic structure of the central Andean subduction zone from local earthquake data, Scientific Technical Report STR01/01, GeoForschungsZentrum Potsdam, 2001. 
Schurr, B., G. Asch, A. Rietbrock, R. Trumbull, and C. Haberland, Complex patterns of fluid and melt transport in the central Andean subduction zone revealed by attenuation tomography, Earth Planet. Sci. Lett., 2002, submitted.

Schwalenberg, K., V. Rath, and V. Haak, Sensitvity studies applied to a two-dimensional resistivity model from the central Andes, Geophys. J. Int., 150, 673-686, 2002.

Soyer, W., and H. Brasse, Investigation of anomalous magnetic field variations in the central Andes of N Chile and SW Bolivia, Geophys. Res. Lett., 28, 3023-3026, 2001.

Thurber, C., Earthquake locations and three-dimensional crustal structure in the Coyote Lake area, central California, J. Geophys. Res., 88, 8226-8236, 1983.

Thurber, C., and D. Eberhart-Phillips, Local earthquake tomography with flexible gridding, Comput.Geosci., 25, 809-818, 1999.

Wessel, P., and W. Smith, New, improved version of the Generic Mapping Tools released, Eos Trans. AGU, 79, 579, 1998.

Whitman, D., B. Isacks, J.-L. Chatelain, J.-M. Chiu, and A. Perez, Attenuation of highfrequency seismic waves beneath the central Andean plateau, J. Geophys. Res., 97, 19,929-19,947, 1992.

Yuan, X., et al., Subduction and collision processes in the central Andes constrained by converted seismic phases, Nature, 408, 958-961, 2000.

Zandt, G., A. A. Velasco, and S. L. Beck, Composition and thickness of the southern Altiplano crust, Bolivia, Geology, 22, 1003-1006, 1994. 
Figure 1. Distribution of PISCO and ANCORP seismological (black diamonds) and MT stations (black circles). White circles depict the epicentres of earthquakes used in tomography. Recent volcanos are indicated by white triangles (WC is Western Cordillera), region enclosed by the dashed line is Altiplano-Puna Volcanic complex (APVC) [de Silva, 1989]. Different shading (from light to dark) indicates topography from 0 to $3000 \mathrm{~m}$, $3000 \mathrm{~m}$ to $4000 \mathrm{~m}$, and above $4000 \mathrm{~m}$ altitude, respectively. Black lines give position of tomographic sections.

Figure 2. In the recovery tests we calculated $t^{*}$ values for the given source (black dots) and receiver (squares) geometry by forward tracing through synthetic $Q^{-1}$ models (depicted by white contours; numbers are $10^{-3} Q^{-1}$ ), and inverted them in the same way as the real data. Synthetic anomalies resemble predominent crustal (top) and mantle (bottom) attenuation. We added normally distributed random noise with a standard deviation of $0.1 t^{*}$ to the synthetic $t^{*}$ data, according to statistical analysis of observed $t^{*}$ values. $Q_{p}^{-1}$ is color-coded, unresolved regions are blanked. Pluses indicate grid nodes. 
Figure 3. Tomographic sections along $20.5^{\circ} \mathrm{S}, 21.0^{\circ} \mathrm{S}$, and $21.5^{\circ} \mathrm{S}$. Seismic $Q_{p}^{-1}$ is color-coded, unresolved regions are blanked. Black triangles indicate the position of recent volcanos. Squares indicate positions of receivers, station corrections are colorcoded. Moho is adapted from Yuan et al. [2000].

Figure 4. (A) Color-coded MT image [Brasse et al., 2002] along $21^{\circ} \mathrm{S}$ with overlaid $10^{-3} Q^{-1}$ (black contours, refer to Fig. 3). Black squares indicate MT stations. (B) Crossplot of $Q^{-1}$ and corresponding $\rho$ values of each 5 by $5 \mathrm{~km}$ bin of the section (within the crust $<50 \mathrm{~km}$ depth), suggesting a correlation between these values (correlation coefficient of -0.71). Different colors demarcate different petrophysical domains with high and low attenuation and resistivity, respectively. Threshold values are indicated by dashed lines. (C) The spatial remapping of the color-coded values reveals different spatial domains with characteristic physical properties (lower and middle Altiplano crust, backarc, forearc). Regions unsresolved by either method are shown faded. 


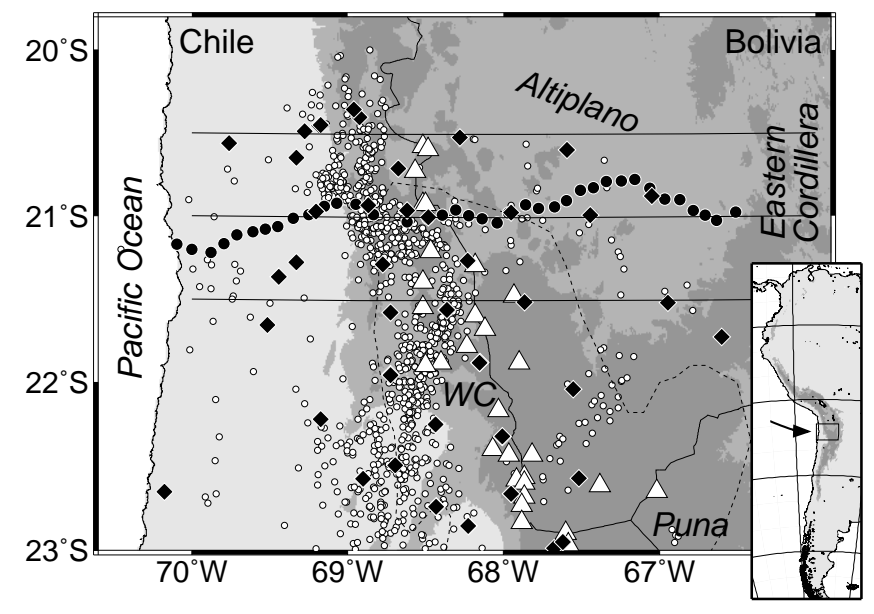

Fig. 1 


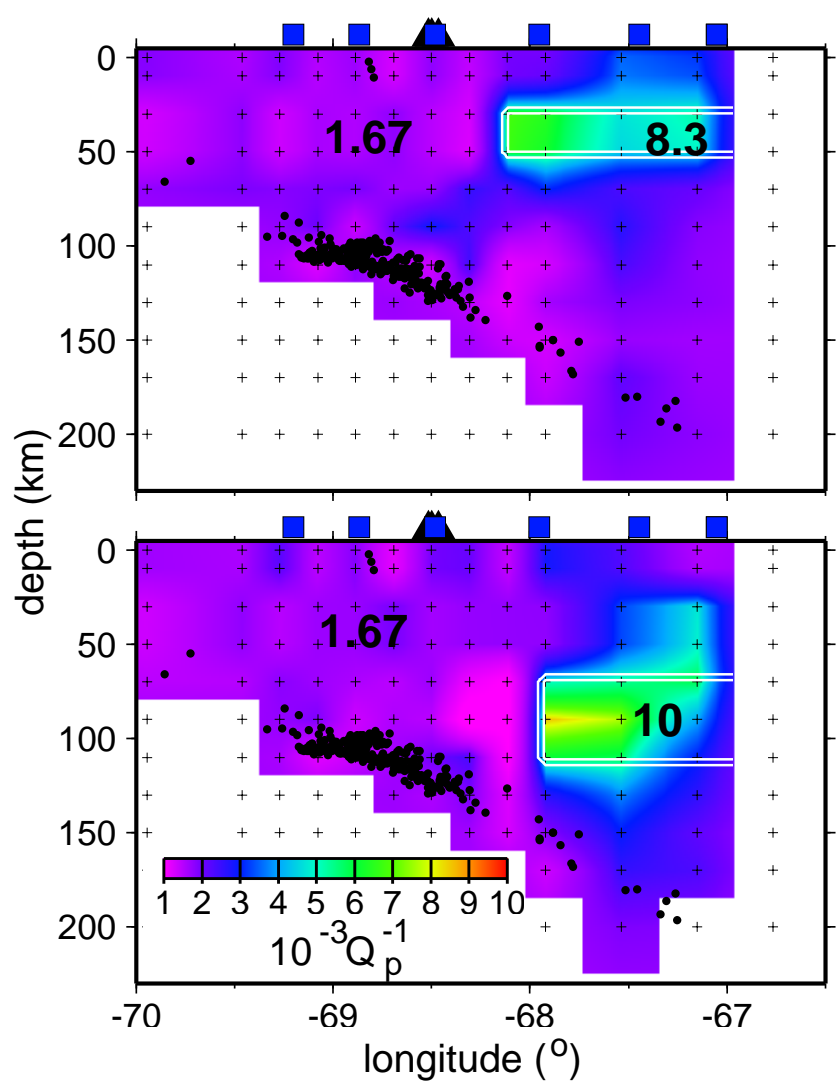

Fig. 2 


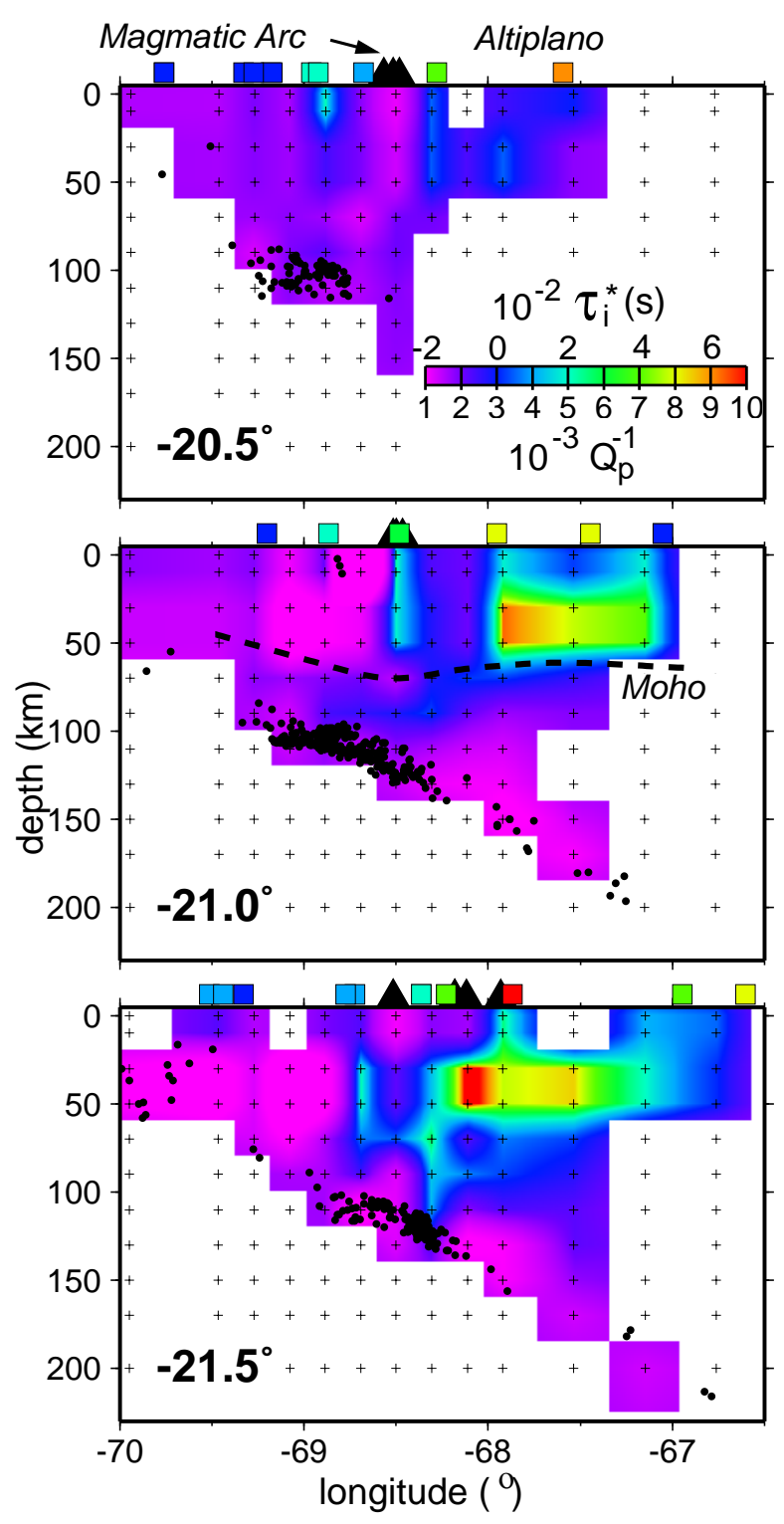

Fig. 3 


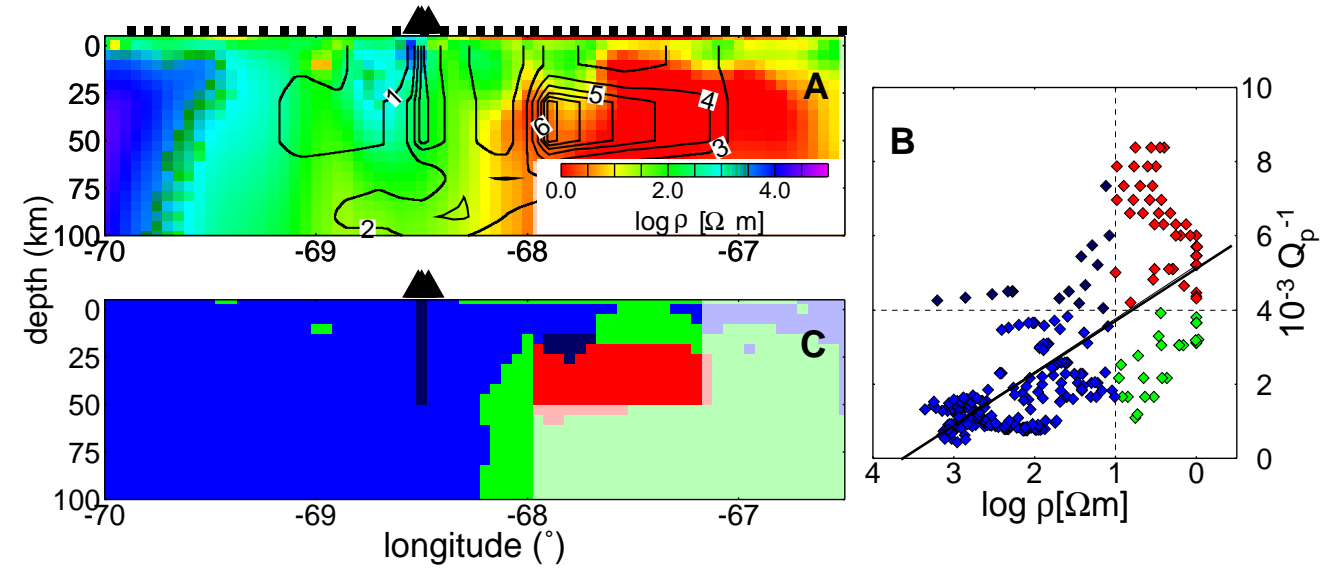

Fig. 4 